\title{
Narrative and Clinical Change in Cognitive-Behavior Therapy: A Comparison of Two Recovered Cases
}

\author{
Miguel M. Gonçalves, João Batista, and Sara Freitas \\ School of Psychology, University of Minho, Braga, Portugal
}

\begin{abstract}
Psychotherapy research suggests that therapeutic change is associated with the emergence and development of innovative moments (IMs) - that is, exceptions to the problematic self-narrative that brought the client to therapy. This study compares two recovered cases of major depression, according to symptom measures, that presented contrasting profiles of evolution of IMs: one typical of successful therapy (Barbara), and another typical of unsuccessful therapy (Claudia). The core conflictual relationship theme (CCRT) was used to study narrative change independently of the innovative moments coding system (IMCS). The results suggest a high congruence between the IMCS and the CCRT profiles. Although Barbara presented changes in the IMCS and the CCRT in a similar way, Claudia's self-narratives (IMs and CCRT), despite symptom change, did not change. The results are discussed, considering the importance of narrative changes in recovery from depression and the maintenance of therapeutic gains.
\end{abstract}

Several scholars and researchers have proposed that meaning is constructed through narrative processes that allow a person to make sense of life experiences (e.g., Angus \& McLeod, 2004; Sarbin, 1986; Singer, 2005). According to this perspective, in psychopathology, problematic selfnarratives block the healthy diversity of meanings and experiences (Dimaggio, 2006; Gonçalves, Matos, \& Santos, 2009; Neimeyer, 2000). Thus, the elaboration of events outside the scope of the problematic self-narrative - that is, the occurrence of exceptions-is considered to be an important process of improving the flexibility of self-narratives, which has also been associated with change in psychotherapy (Alves, Mendes, Gonçalves, \& Neimeyer, 2012; Angus \& Greenberg, 2011; Polkinghorne, 2004). To evaluate the process of narrative change in psychotherapy, Gonçalves, Ribeiro, Mendes, Matos, and Santos (2011) developed the innovative moments coding system (IMCS), which identifies exceptions to the problematic self-narrative experienced by clients throughout treatment, called innovative noments (IMs). IMs are categorized into five types: action, reflection, protest, reconceptualization, and performing change, as illustrated in Table 1.

Using the data from several studies that employed the IMCS (Gonçalves et al., 2012; Gonçalves, Mendes, Ribeiro, Angus, \& Greenberg, 2010; Mendes et al., 2010; Ribeiro, Gonçalves, \& Ribeiro, 2009; Santos, Gonçalves, \& Matos, 2010; Santos, Gonçalves, Matos, \& Salvatore,

Received 3 March 2015; accepted 12 December 2015.

Address correspondence to Miguel M. Gonçalves, CIPsi - Psychology Research Center, Psychotherapy and Psychopathology Research Unit, School of Psychology, University of Minho, Minho, 4710 Braga, Portugal. E-mail: mgoncalves@psi.uminho.pt 
TABLE 1

Innovative Moments Grid (Version 7.2)

Types of IMs
Action
Actions or specific behaviors against the problem(s)
Reflection
Thinking processes that indicate the understanding of
something new that creates a change in the
problematic pattern (e.g., thoughts, intentions,
interrogations, and doubts)

\section{Protest}

Moments of critique, which involve some kind of confrontation (directed at others or versions of oneself), which could be planned or actual behaviors, thoughts, or feelings

Reconceptualization

Process description, at a meta-cognitive level (the client not only manifests thoughts and behaviors outside the problematic narrative but also understands the processes involved in it)

Performing change

References to new aims, experiences, activities, or projects, anticipated or in action, as consequences of change

New coping behaviors facing obstacles
Effective resolution of unsolved problem(s)
Active exploration of solutions
Strategies implemented to overcome the problem
Comprehension-reconsidering causes of problems
and/or awareness of their effects
New problem(s) formulations
Adaptive self-instructions and thoughts
Intention to fight problem(s') demands, references of
self-worth and/or feelings of well-being
Therapeutic process-reflecting about the therapeutic
process
Change process - considering the process to overcome
the problem(s); references of self-worth or feelings of
well-being (as consequences of change)
New positions-references to new/emergent identity
versions in the face of the problem(s)
Position of critique in relation to the problem(s) or the
others who support it (the other could be an
internalized other or facet of oneself)
Positions of assertiveness and empowerment
Repositioning oneself toward the problem(s)
Reconceptualization always involves two dimensions:
A .Description of the shift between two positions (past
and present)
B .The process underlying this transformation
Generalization to the future and other life dimensions of
good outcomes
Problematic experience as a resource for new situations
Investment in new projects as a result of the process of
change
Investment in new relationships as a result of the
New skills unrelated to the problem
Reemergence of neglected or forgotten self-versions
a

New coping behaviors facing obstacles

Active exploration of solutions

Strategies implemented to overcome the problem and/or awareness of their effects

New problem(s) formulations

Adaptive self-instructions and thoughts

Intention to fight problem(s') demands, references of

process

Change process - considering the process to overcome the problem(s); references of self-worth or feelings of well-being (as consequences of change)

New positions-references to new/emergent identity others who support it (the other could be an internalized other or facet of oneself)

Positions of assertiveness and empowerment

Repositioning oneself toward the problem(s)

Reconceptualization always involves two dimensions:

.Description of the shift between two positions (past

Generalization to the future and other life dimensions of outcomes

Problematic experience as a resource for new situations

Investment in new projects as a result of the process of

process of change

Reemergence of neglected or forgotten self-version

Note. From the Innovative Moments Coding System (Gonçalves, Ribeiro, Mendes, Matos, \& Santos, 2011). Adapted with permission.

2009) and analyzing different samples (e.g., major depression, victims of intimate violence), in different therapeutic modalities (e.g., emotion-focused therapy, narrative therapy), a heuristic model of narrative change in psychotherapy was developed (Gonçalves et al., 2009; Matos, Santos, Gonçalves, \& Martins, 2009). According to this model, action, reflection, and protest IMs are the first types of innovation to occur among recovered cases, representing the first signs of alternative experiences. Reconceptualization IMs appear later in the treatment, facilitating 
the emergence of a position of authorship, as it is composed of two interrelated dimensions: a contrast between a problematic past and an emerging alternative present, and an identification of the change processes involved in that contrast. Performing change IMs involve new experiences projected in the future, allowing the expansion of the change process. In unchanged cases, reconceptualization and performing change IMs are rarely found, or have a low presence. Moreover, the global proportion of IMs has been found to be consistently higher in recovered than in unchanged cases.

Narratives may be conceived at different levels of organization, from the conversational layer (IMs in the therapeutic conversation) to the intermediate level of self-narratives (a story told in therapy), and to the highest level of life stories and culturally shaped narratives (Angus, Levitt, \& Hardtke, 1999; Gergen \& Gergen, 1997). According to this framework, IMs (i.e., micro-narrative changes) are the building blocks of new self-narratives (i.e., macro-narrative changes), and those self-narratives are the building blocks of a life story.

In the present article, our aim is to study the association between the first two layers of narrative organization (i.e., micro- and macro-narrative changes) and their relationship with symptom change. Whereas the micro-narrative evolution was tracked through the IMCS, the macro-narrative changes were identified using the core conflictual relationship theme (CCRT) method (Luborsky, 1998). The CCRT analyzes the relational patterns, relatively stable throughout life (Luborsky, 1998), that operate as templates or scripts (e.g., Demorest, Crits-Christoph, Hatch, \& Luborsky, 1999) driving people's interactions with others. As such the CCRT gives us access to the macro-narrative level. Importantly, research with both the IMCS and the CCRT suggests that change in narratives, assessed through the IMCS or the CCRT, is closely associated with changes in symptoms (e.g., Crits-Christoph \& Luborsky, 1998; Gonçalves et al., 2011).

\section{RELATIONAL NARRATIVES: THE CCRT METHOD}

According to Luborsky, Barber, and Diguer (1992), relational narratives reflect the client's deeper relationship patterns. Luborsky (1998) developed the CCRT to derive these relational patterns from the stories clients tell during psychotherapy. The CCRT unit of analysis is therefore the relational episode, defined as a discrete narration describing interactions between the client and others, including the self and the therapist (Luborsky, 1998). The CCRT is defined by the combination of the most frequent of three components: wishes (wishes, intentions, or desires of the client in the described interaction), response of other (others' perceived or expected reaction to his or her wishes), and response of self (client's reaction to others' responses and the satisfaction, or not, of his or her wishes).

The CCRT method allows the identification of the pervasiveness of the relational patterns (Crits-Christoph \& Luborsky, 1998), which is defined as the frequency of a given component in the client's relational episodes. According to Crits-Christoph and Luborsky (1998), a CCRT with less pervasiveness is more flexible and contains less frequent and repetitive conflicts between the client's wishes, the responses of other, and the responses of self. Another central CCRT dimension is the responses' (of other and of self) valence, which can be positive (e.g., self-confident), when the client does not expect or perceives an interference with wish actualization, or negative (e.g., helpless), when such interference is perceived or anticipated (Ciaglia, 2010). 
Luborsky and colleagues (1992) argued that in successful psychotherapy, changes in the responses of other and of the self are more common than changes in wishes. Thus, a successful transformation of the CCRT present at the beginning of therapy is achieved by a decrease in negative responses and an increase in positive responses (of other and of self; Crits-Christoph \& Luborsky, 1998; McMullen \& Conway, 1997). Several studies (e.g., Bressi et al., 2000; Cierpka et al., 1998) further suggested that these indicators are associated with symptomatic improvement. Despite its psychodynamic origins, the CCRT method has been applied to analyze several therapeutic modalities, such as interpersonal (Crits-Christoph et al., 1999), psychodynamic (CritsChristoph \& Luborsky, 1998), and cognitive (Crits-Christoph, Demorest, Muenz, \& Baranackie, 1994). Interestingly, Crits-Christoph and colleagues (1994) showed that the pervasiveness of themes was not different in cognitive and dynamic therapy, and that the individual differences found in the CCRT were significantly associated with treatment length but not with its modality. These studies suggest that the CCRT framework can be applied to study therapy modalities in which interpersonal change is not a focus of the treatment, or in which the CCRT is not used as a therapeutic tool. This was also what occurred in the present study, in which a cognitive-behavior therapy (CBT) protocol was followed.

\section{Narrative Change in Psychotherapy}

The claim that narrative changes are related to symptomatic recovery in psychotherapy and general well being has received a strong body of evidence in the last decades (e.g., Adler, 2012; Baerger \& McAdams, 1999; Lysaker, Lancaster, \& Lysaker, 2003; Pennebaker, 1993). Recently, Angus and Kagan (2013) argued that the narration, understanding, and integration of self-narratives may be the key to an adaptive identity and flexible view of the self.

Reinforcing this view, the impact of processes of narrative change has been shown not only on mood disorders such as depression (e.g., Gonçalves, Ribeiro, Silva, Mendes, \& Sousa, 2015; Mendes et al., 2010) and in grief therapy (Neimeyer, Herrero, \& Botella, 2006) but also on schizophrenia (Lysaker, Ringer, Maxwell, McGuire, \& Lecomte, 2010) and personality disorders (Dimaggio, Montano, Popolo, \& Salvatore, 2015).

More specifically, Lysaker and colleagues (2010) found that aspects of client narratives were associated with the quality and quantity of social relationships. The dimensions of social worth and agency of the narratives were most associated with the social relationship's quality. The authors considered therefore that their results are consistent with the notion that changes in personal narratives are an important domain of recovery in schizophrenia. Using a similar approach, Dimaggio and colleagues (2015) considered the change of narrative styles to be at the core of personality disorder therapy. Accordingly, changes in interpersonal schemas are central, as these involve rigid and dysfunctional interpretations that prevent alternative views of others and the self. These authors not only considered the importance of factors such as metacognition, agency, and narrative integration but also the role of interpersonal schemas. These schemas are subjective representations of interactions with others, guided by the person's wishes and expectations, generating rigid and dysfunctional interpretations that prevent alternative views (Dimaggio et al., 2015). Similarly to the CCRT framework, these schemas lead clients to rigid and stereotyped interpretations of interpersonal interactions.

The change of clients' narratives in psychotherapy has also been operationalized as an improvement in coherence (Neimeyer et al., 2006) and in the integration of negative experiences 
(Angus \& Kagan, 2013). Moreover, when this effort of coherence and integration is successful, the client's agency and metacognitive abilities are enhanced (Dimaggio, Salvatore, Azzara, \& Catania, 2003), leading to more flexible self-narratives and more satisfying interpersonal relationships. Ultimately, the change of clients' narratives can have an impact on the deeper maladaptive schemas (Young, 1999) or interpersonal patterns (Crits-Christoph \& Luborsky, 1998). Psychotherapy can thus be considered a form of rewriting the client's self-narratives (Dimaggio et al., 2003). In this sense, change in clients' narratives is considered as a factor associated not only with recovery but also with the maintenance of therapeutic gains (Angus \& Kagan, 2013).

Despite analyzing different narrative levels, we expect that the more flexible and integrated the micro-narrative changes (IMs) are, the more impact they will have on the client's relational patterns (core conflictual relationship theme). More specifically, we expect that the deeper narrative changes will be associated with a higher proportion of complex IMs (reconceptualization and performing change) and a more flexible (less pervasive) and a more positive interpersonal pattern identified by the CCRT. Moreover, when there are more narrative changes (both at micro and macro levels), the more stable and pronounced will be the changes in the symptomatic measures.

\section{The Present Study}

In this study we selected from a sample of CBT patients (Lopes et al., 2014) two contrasting cases: a recovered case in which reliable symptom change occurred with the expected IMs pattern (typical case), and a case in which reliable symptom changes occurred without significant IMs changes (atypical case). Narrative micro-changes (IMs) were compared with narrative macrochanges (CCRT) to explore whether in the atypical case a broader narrative change occurred without the corresponding IM changes (an anomalous finding) or whether changes in symptoms occurred without significant narrative transformations at both the level of IMs and the level of CCRT. We hypothesize that the patterns of IMs and the CCRT are congruent in both cases. That is, we expect that in the atypical case a pre-post change in symptoms has occurred without significant narrative changes, both at the level of the IMs and at the level of the CCRT. On the contrary, we expect that in the typical case pre-post changes are congruent, at the level of narrative change (IMs and CCRT) and at the level of symptom change. Moreover, if changes in IMs and the CCRT are congruent, an important question is if the atypical case has a less stable change than the typical one.

\section{METHOD}

\section{Clients}

Both clients were diagnosed with major depressive disorder at Axis I according to the DSM-IV$T R$ (American Psychological Association, 2002), without any comorbidity on Axis II. Although not having an Axis II diagnosis, Claudia presented traits of dependent and avoidant personality, whereas Barbara did not present any Axis II traits. More specifically, Claudia presented three traits of personality disorders. According to Dimaggio and colleagues (2013), who considered five groups of personality disorders traits $(0-4,5-9,10-14,20$ or more), both clients are in the first of the considered groups, although Claudia showed more traits than Barbara. These cases 
were selected from a sample composed of 10 patients ( 5 recovered and 5 unchanged), chosen for process research, who were part of a larger controlled clinical trial (Lopes et al., 2014). Both cases were recovered, according to the reliable change index criteria (RCI, Jacobson \& Truax, 1991) of the Beck Depression Inventory (BDI-II, Beck, Steer, \& Brown, 1996; more on this below).

Claudia was the only recovered case of the CBT subsample without significant narrative changes (according to the IMCS). This is why we chose Claudia, as she was the only case studied so far who had pre-post clinical significant changes without the corresponding pattern of IM changes. Barbara was randomly chosen from the other typical cases, in which symptom change and IM changes cooccurred as expected. Both names are fictional in order to maintain the clients' confidentiality.

At the time of therapy, Claudia was a divorced 39-year-old, living with her 9-year-old daughter. Although she was a teacher, she was on sick leave because of repeated lateness and absences, a situation that lasted until the end of therapy. Claudia's problematic self-narrative was characterized by her inability to comply with working hours and task dispersion, both exacerbated by a perceived difficulty in defining priorities. Combined with reported concentration and memory difficulties, these characteristics resulted in repeated incidents of procrastination and task avoidance. Finally, the client also reported difficulties in maintaining intimate relationships and feelings of loneliness.

At the time of therapy, Barbara was a divorced 26-year-old, living with her parents. She had finished her university course and was looking for a job. During the period of therapy she had several part-time professional experiences, despite not finding a full-time job. Barbara's problematic self-narrative was heavily marked by her recent divorce, which was still unresolved due to litigation concerning asset sharing with her ex-husband. This situation was causing several interpersonal conflicts, with her ex-husband, his family, and her own family, which she viewed as very stressful. Encompassing these recent events was Barbara's general lack of assertiveness and empowerment, associated with an overvaluation of other people's opinions. Finally, she also reported deep fears of trusting other people again (especially men, as her ex-husband had abused her psychologically) and the need to reorganize her life.

\section{Treatment}

Both clients agreed to participate in a controlled clinical trial (Lopes et al., 2014) that compared the effects of narrative therapy (White \& Epston, 1990) and cognitive-behavioral therapy (CBT; Beck, Rush, Shaw, \& Emery, 1979). They were informed about the study's goals and signed an informed consent form. Both clients were assigned to undergo a CBT protocol for depression of 20 sessions; Claudia attended 19 sessions, whereas Barbara completed 20. All sessions were videotaped.

\section{Therapist}

The therapist was a male doctoral student in clinical psychology with 5 years of clinical experience, who was supervised by a more experienced therapist, with over 15 years of clinical experience and wide experience as a clinical supervisor. The weekly supervision was the common 
criterion used with these two cases, to ensure that the treatment complied with the model (see Lopes et al., 2014, for further details about the clinical trial).

\section{Researchers/Coders}

The IMs coding was performed by two judges, both doctoral students with over a year of clinical experience, after completing the IMCS training. This coding was done previously to this study (Gonçalves et al., 2015). The training comprised the completion of three workbooks in which the judges had to identify the IMs and IM types in clinical vignettes. Then, the judges coded a sample of full therapeutic sessions. The training was successfully completed when each judge obtained a Cohen's kappa higher than .70 .

The CCRT coding was done by a doctoral student (with 8 years of clinical experience), who also coded the IMs, and a master's student (with 1 year of clinical experience). Prior to the coding, both judges also completed a CCRT training that included extensive reading of Luborsky and Crits-Christoph's (1998) guidelines and examples of several clinical sessions to adequately locate relational narratives and identify the CCRT components. The training was considered successfully completed when a percentage of agreement for the relational narratives identification higher than $90 \%$ and an intraclass correlation for the components definition higher than .80 were reached. Despite the fact that there was a common judge in both codings, these were conducted with a time lapse of 2 years, the systems have different approaches to coding, and the reliability was high in both, which reduced the possibility of bias. Finally, all of the judges involved were unaware of the clients' outcomes and the purpose of the study.

\section{Measures}

Structured clinical interviews for DSM-IV-TR Axis I disorders (SCID-I; First, Spitzer, Gibbon, \& Williams, 2002) and Axis II disorders (SCID-II; First, Gibbon, Spitzer, Williams, \& Benjamin, 1997). The SCID-I and II are structured clinical interviews based on the diagnostic criteria of the DSM-IV-TR (APA, 2002), which evaluates clients' Axis I and II symptoms. They were administered during a pretherapy evaluation session.

Beck Depression Inventory (BDI-II; Beck et al., 1996; Portuguese version adapted by Coelho, Martins, \& Barros, 2002). This inventory is composed of 21 items that evaluate depressive symptoms and was administered every fourth session and in the follow-up sessions (18 and 30 months after therapy). The items are rated on a 4-point Likert scale (0-3), and the total score ranges between 0 and 63 points. Higher values in the BDI-II correspond to higher depressive symptomatology. The inventory has a high internal consistency of .91 (Steer, Brown, Beck, \& Sanderson, 2001). The cut-off for significant depressive symptoms is 14.29 , and the reliable change index (RCI; Jacobson \& Truax, 1991), indicating clinically significant change, is 8.46 (Seggar, Lambert, \& Hansen, 2002).

Outcome questionnaire (OQ-45.2; Lambert et al., 1996; Portuguese version adapted by Machado \& Klein, 2006). This 45-item questionnaire is divided into three subscales (symptomatic, interpersonal, and social) and assesses clinical progress. It was administered every fourth session and at the two follow-up sessions (18 and 30 months after therapy). The items are rated on a 5point Likert scale (0-4), and the total score ranges between 0 and 180 points. Higher values in the 
OQ-45.2 correspond to higher general psychological distress. The questionnaire has good test-retest reliability (.84) and a high internal consistency (.93; Lambert et al., 1996). The Portuguese version (Machado \& Fassnacht, 2015; Machado \& Klein, 2006) used in this study has a high internal consistency, with a cutoff score of 62 and an RCI (Jacobson \& Truax, 1991) of 18 .

Innovative moments coding system (IMCS; Gonçalves et al., 2011). The IMCS is a coding system that divides observed IMs into five categories. A higher proportion (in previous articles this proportion was termed salience) of IMs is associated with a higher presence of alternative experiences to the problematic self-narrative. A higher proportion of reconceptualization and performing change IMs is associated with the narrative innovations typical of recovered cases. Studies that have used the IMCS (Gonçalves et al., 2012; Matos et al., 2009; Mendes et al., 2010) produced interjudge agreements that ranged between .86 and .97 .

Core conflictual relationship theme (CCRT; Luborsky \& Crits-Christoph, 1998; translated by Batista, Alves, Freitas, \& Machado, 2012). The CCRT is a content analysis system that identifies relationship episodes narrated by the client during therapy and distinguishes the three components (wishes/needs, response of other, response of self) of each relational episode. After the initial coding, the components are converted to the standard categories proposed by Barber, Crits-Christoph, and Luborsky (1998). A higher pervasiveness and a negative valence of the components are indicative of more rigid and less adaptive relational patterns.

\section{Procedures}

IMCS. As previously mentioned, the IMs were coded before this study (Gonçalves et al., 2015). Here we summarize the main procedures of the coding process. After receiving training in the IMCS, two judges viewed the video recordings of the initial sessions and reached a mutual agreement on the main features of the client's problematic self-narrative. Then, working with transcripts of the sessions, they independently coded the IMs, defined as novelty elements (exceptions to the problematic self-narrative), tracked their proportion (that is, proportion of text involved in their description or elaboration), and identified their type. The reliability was based on the initial (independent) coding of the sessions. In this study, reliability on IM identification was $85.9 \%$ for Claudia and $95.7 \%$ for Barbara. The reliability of IM types was calculated through Cohen's kappa and was .97 for Claudia and .92 for Barbara. When disagreement occurred, the final coding was the result of consensus between the judges, with the help of an external auditor with IMCS experience.

CCRT. Two judges independently coded the CCRT. In order to track the existence of changes in the relational patterns throughout therapy, the CCRT method was applied at three temporal moments: the beginning, middle, and end of therapy. Two sessions from the initial (2nd and 3rd), two from the middle (10th and 11th), and two (three for Claudia) from the final phase of therapy (18th and 19th for Barbara; 16th, 17th, and 18th for Claudia) were selected and coded. It was necessary to analyze three sessions from the final phase of Claudia's treatment to ensure that a minimum of 10 relational episodes were used to define the CCRT, as suggested by Luborsky (1998).

The CCRT coding followed the procedures described by Luborsky (1998). First, the relationship episodes were identified independently by the two judges, who then met to decide which episodes were to be coded. This decision was based on an episode's degree of completeness, 
TABLE 2

Standard Categories for the CCRT Components (Edition 3)

\begin{tabular}{lll}
\hline Wishes & \multicolumn{1}{c}{ Response of other } & Response of self \\
\hline To assert self \& be independent & Strong & Helpful \\
To oppose, hurt, and control others & Controlling & Unreceptive \\
To be controlled, hurt, and not responsible & Upset & Respected and accepted \\
To be distant and avoid conflicts & Bad & Oppose and hurt others \\
To be close and accepting & Rejecting and opposing & Self-controlled and self-confident \\
To be loved and understood & Helpful & Helpless \\
To feel good and comfortable & Likes me & Disappointed and depressed \\
To achieve and help others & Understanding & Anxious and ashamed \\
\hline
\end{tabular}

Adapted from Barber, Crits-Christoph, and Luborsky (1998).

which was rated on a scale from 1 to 5 , with a cutoff at 2.5. Next, the components were identified and converted into one of the standard eight categories based on their proximity to it. These categories, listed in Table 2, constitute clusters theoretically derived from empirical research with the CCRT (Barber et al., 1998). Each response's valence was analyzed according to the procedures described by Wilczek, Weinryb, Barber, Gustavsson, and Åsberg (2004). Instead of deciding whether a response was positive or negative, it was assumed that "response of other" clusters 1 (strong), 6 (helpful), 7 (likes me), and 8 (understanding), and "response of self" clusters 1 (helpful), 3 (respected and accepted), and 5 (self-controlled and self-confident) are positive and all others are negative. Because there are no neutral categories, the sum of positive and negative responses is always $100 \%$. Agreement on the identification of relationship episodes was $88 \%$ in both cases. Intraclass correlation for the identification of wishes, response of other, and response of self was, respectively, .90, .89, and .89 for Claudia; and .96, .93, and .98 for Barbara.

\section{RESULTS}

Given the criteria for case selection described above, the results of the BDI-II and of the IMs are the expected ones. As stated, we selected Claudia as she was the only case studied so far with the IMCS with incongruent results: She was recovered according to the BDI-II, but unchanged according to the IMCS. As with all the other typical recovered cases, Barbara's BDI-II and IMCS results were congruent - that is, she had a profile of a recovered case according to the IMCS and she was also a recovered case according to the reliable change index on the BDI-II. We present first the results of the BDI-II and of the IMCS, and then the CCRT, to compare the narrative changes in the IMCS with the narrative changes in the CCRT. We finalize the results sections with the evolution of the OQ-45.2 subscales in order to have a more fine-grained analysis of the changes in both clients.

\section{Symptom Evaluation on BDI-II}

The BDI-II results (Figure 1) indicated that clinical recovery had occurred between pre- and posttherapy in both cases, suggesting that the therapeutic changes were clinically reliable and 


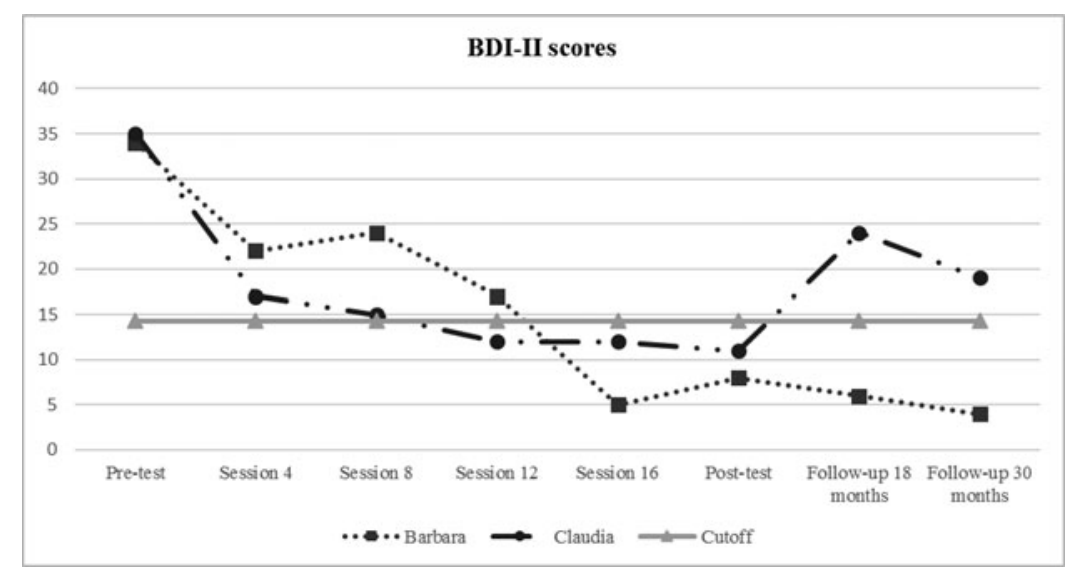

FIGURE 1 Client's BDI-II scores evolution.

that at the end of treatment the clients scored within the range of a functional population (Jacobson \& Truax, 1991). This evolution of the BDI-II scores was what led us to consider these cases as recovered. However, the clients were also evaluated at 18- and 30-month follow-up. During this period, Claudia's (the atypical case) depressive symptoms slid back within the range of the clinical population (i.e., above 14.29 points), indicating a relapse. On the other hand, Barbara's scores maintained the decreasing tendency, continuing to be within the range of the functional population.

\section{Innovative Moments (IMs)}

The main results of the IMCS are shown in Table 3.

Whereas Barbara presented an overall proportion of IMs throughout the treatment of $28.58 \%$, Claudia's overall results reached only $8.99 \%$. The IM type with the highest proportion in both cases was reflection. Barbara's profile exhibited a higher diversity of IMs (with only action being residual) than Claudia's, who had no performing change IMs and a residual proportion of action, protest, and reconceptualization IMs.

In sum, despite the fact that both cases were recovered cases according to the BDI-II, it is clear that their narrative innovation profiles were distinct. Whereas Barbara presented a typical

TABLE 3

IMCS Results

\begin{tabular}{|c|c|c|c|c|c|c|}
\hline Proportion/client & Overall IMs & Action IM & $\begin{array}{l}\text { Reflection } \\
\text { IM }\end{array}$ & Protest IM & $\begin{array}{l}\text { Reconcep- } \\
\text { tualization } \\
\text { IM }\end{array}$ & $\begin{array}{l}\text { Performing } \\
\text { change IM }\end{array}$ \\
\hline Barbara & $28.58 \%$ & $0.52 \%$ & $18.13 \%$ & $4.07 \%$ & $3.23 \%$ & $2.58 \%$ \\
\hline Claudia & $8.99 \%$ & $0.99 \%$ & $7.60 \%$ & $0.05 \%$ & $0.34 \%$ & $0.00 \%$ \\
\hline
\end{tabular}

Note $: \mathrm{IM}=$ innovative moments. 


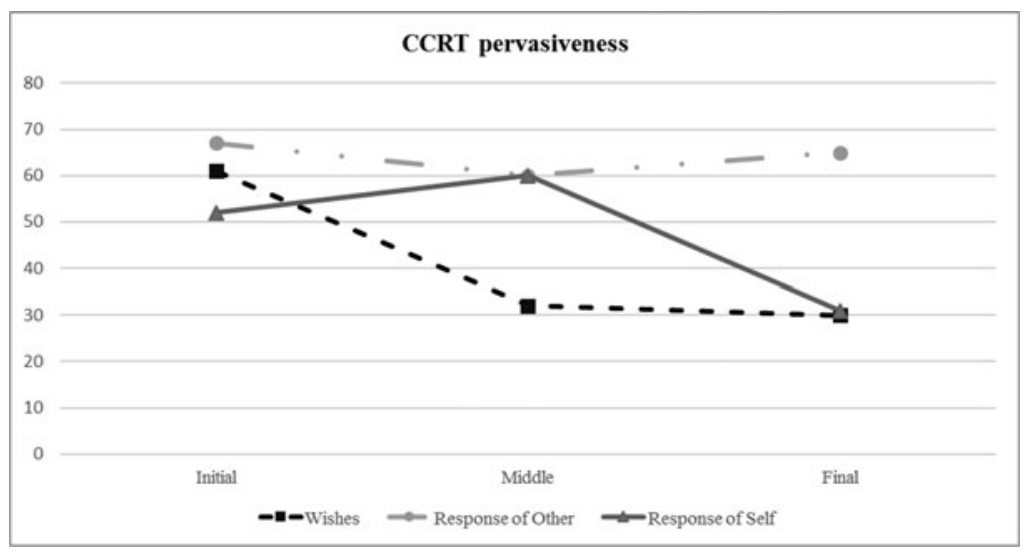

FIGURE 2 Barbara's CCRT components pervasiveness.

profile of a recovered case, with an overall proportion of IMs of around 30\% and all types of IMs (with reconceptualization and performing change appearing from the middle to the end of therapy), in Claudia's profile there was a low IM diversity and low overall proportion. According to the innovative moments model, this profile is typical of an unchanged case (e.g., Gonçalves et al., 2009; Gonçalves et al., 2012; Mendes et al., 2010), as the two main features congruent with an unchanged case are (a) a low IM diversity across sessions (with some of them rare or even absent) and (b) a low (if any) proportion of reconceptualization.

\section{Core Conflictual Relationship Theme}

The results of CCRT pervasiveness are shown in Figures 2 and 3. The profiles of both clients are very different on the wishes and on the response of self components, being more similar in the responses of other.

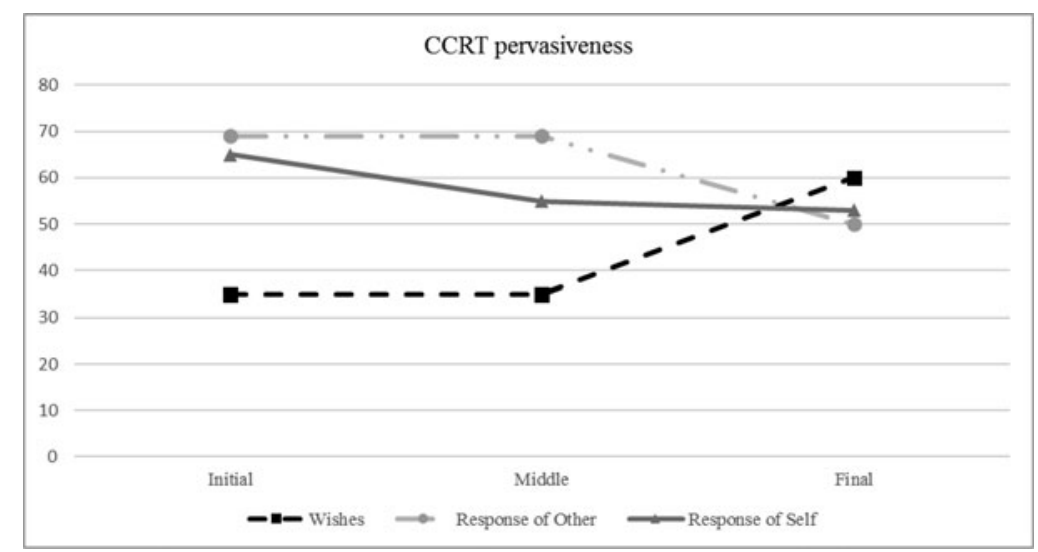

FIGURE 3 Claudia's CCRT components pervasiveness. 
Considering the wishes component, we can see how it had opposite tendencies in these clients. Barbara's dominant wishes evolved from to be loved and understood in the initial sessions, to the self-oriented wish to assert self and be independent in the middle phase, and to be loved and understood again in the final phase, but with a decrease in its pervasiveness (61 to 30\%). Claudia's wishes, on the other hand, were more flexible in the initial and middle sessions (with two categories equally as most frequent, to be loved and understood and to achieve and help others, with $35 \%$ of pervasiveness) and became more pervasive in the final phase of therapy, to achieve and help others being the most prevalent wish in $60 \%$ of the relational episodes.

The response of other component presented a stable pattern throughout therapy in both clients, rejection and opposition being the most pervasive category in all therapy phases. The response component valences of the response of others were also not very different between clients. Barbara's positive response of other was very low in the initial sessions (10\%), increasing in the middle sessions (27\%), and dropping in the final sessions (17\%). On the other hand, Claudia's positive response of other was similar in the initial and middle sessions (23\% and $21 \%$, respectively), and had a small increase in the final sessions (30\%).

Contrarily to the similarity of the response of other in both cases, the response of self component depicts different profiles between the cases. The helpless category, which includes reactions of insecurity, ambivalence, or dependency, was the most pervasive in Barbara's initial and middle sessions (with $52 \%$ and $65 \%$, respectively), but in the final sessions there was not only a more flexible response of self ( $31 \%$ of the relational episodes) but also a change in the most frequent category, which became self-controlled and self-confident-a category composed of positive reactions. On the other hand, helpless was Claudia's most pervasive response of self throughout therapy, with a slight decrease of its presence in relational episodes from the initial (65\%) to the middle $(55 \%)$ and the final $(53 \%)$ sessions. These differences are also reflected at the level of this component's valence. Thus, Barbara's positive response of self showed an increase from the initial (13\%) to the middle (23\%), becoming high in the final sessions $(61 \%)$; whereas Claudia's showed a slight increase throughout therapy, from $12 \%$ in the initial and $15 \%$ in the middle to $27 \%$ in the final sessions.

\section{OQ-45.2 Subscales}

Claudia (the atypical case) showed a clinically meaningful evolution on the symptom subscale, as her score decreased from 65 to 39 , exceeding the 12 points needed for a reliable change. However, the scores on the interpersonal and social subscales did not reach the reliable cutoff requirement ( 8 and 7 points, respectively), decreasing from 23 to 16 on the first subscale and from 16 to 11 on the second. Barbara, on the other hand, showed a dramatic evolution on the symptom subscale (from 54 to 7), also reaching the reliable cutoff requirement in the interpersonal and social subscales (from 21 to 3 and from 20 to 1 , respectively). These results are presented in Figures 4 and 5.

\section{DISCUSSION}

This article aimed to compare two cases in which symptom recovery was associated with different IM profiles: one typical (Barbara) and one atypical case (Claudia). The CCRT method was used to 


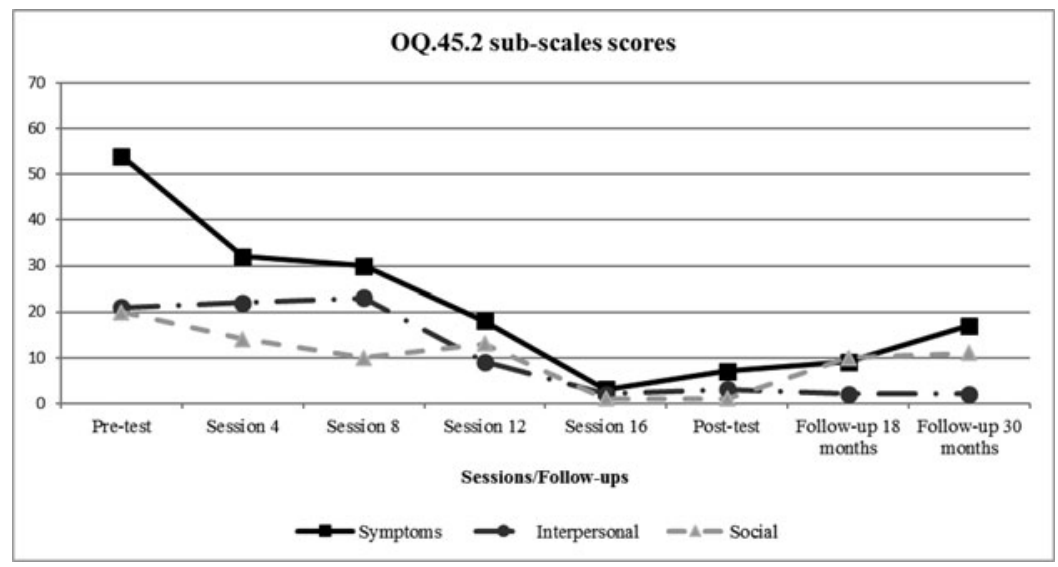

FIGURE 4 Barbara's OQ.45.2 subscales scores evolution.

determine whether there were changes in the broader self-narratives in both cases, congruent with the symptomatic changes, or if the pattern of the CCRT was congruent with the IMCS results. If the CCRT and the IMCS were congruent, we would expect the occurrence of narrative changes in the typical but not in the atypical case. In other words, we explored if Claudia (the atypical case) had significant changes in her self-narratives that were not detected by the IMCS but were detected with the CCRT, which would be an anomalous finding; or if she had recovered from the depressive symptoms without a deeper narrative transformation. This was done comparing Claudia to another case, Barbara, who presented a typical IMCS recovered case profile, congruent with the changes in symptoms.

The CCRT results indicated that these cases had a different evolution in their relationship patterns, supporting our expectation that changes in IMCS and in the CCRT are consistent.

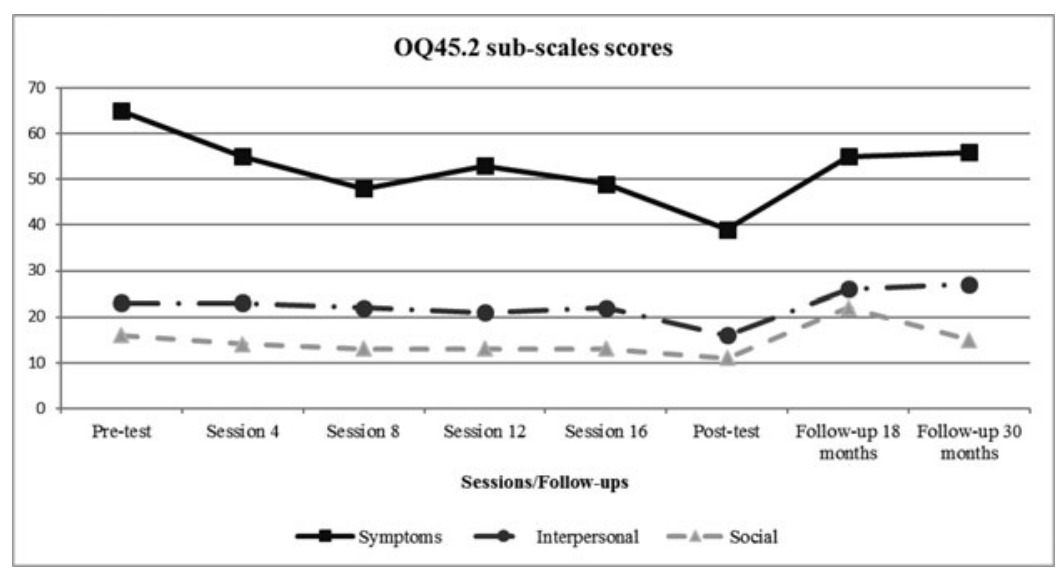

FIGURE 5 Claudia's OQ.45.2 subscales scores evolution. 
Whereas Barbara's results showed more flexible wishes and response of self components, Claudia's wishes pervasiveness was higher in the final sessions and her response of self was less flexible than Barbara's. Moreover, considering the valence of the relationship patterns, it is clear that Barbara's response of self became positive (and the most frequent category), whereas this did not happen with Claudia. Claudia had only a slight increase in response of self positive valence, continuing to respond to her interpersonal events mostly with reactions of incapacity, insecurity, and ambivalence (which constituted $73 \%$ of her responses). Despite the difficulty of making comparisons between cases with the CCRT, previous research has consistently shown that the decrease of response of other and response of self pervasiveness, and increase of positive valence are strongly associated with a decreased symptom severity (Cierpka et al., 1998) and a successful therapeutic outcome (Crits-Christoph \& Luborsky, 1998; Grenyer \& Luborsky, 1996). A more flexible and positive response of self has also been related to an increased sense of mastery (Grenyer \& Luborsky, 1996) - that is, the client's ability to deal with interpersonal distress and conflicts. Finally, Cierpka and colleagues (1998) also found an association between less pervasive wishes and higher well-being. All of these findings from previous research suggest that Barbara achieved a more flexible and positive interpersonal pattern than Claudia, consistent with Luborsky and Crits-Christoph's (1998) theoretical model underlying the CCRT, in which the maladaptive relationship episodes should decrease during therapy, resulting in a more functioning central pattern. This assertion is substantiated by the clients' OQ.45.2 subscales: whereas Barbara reached a clinically significant change on all of the subscales, Claudia only reached significant change on the symptom subscale. Thus, Claudia did not reach meaningful changes in her deeper patterns, including the interpersonal milieu.

Thus, the IMCS results were congruent with the clients' interpersonal pattern changes, as detected by the CCRT. Whereas in Claudia's sessions the identified IMs were less diverse and less frequent than are typically observed in recovered cases, Barbara presented a higher IMs diversity and frequency, alongside a higher proportion of reconceptualization and performing change IMs, all features of recovered cases (e.g., Gonçalves et al., 2011). We suggest that in Barbara's case the narrative innovation fostered by these more complex IMs (reconceptualization and performing change) led to new ways of interpreting and reacting to events (including to interpersonal ones), which in turn are reflected in the changes of interpersonal patterns (evaluated by the CCRT).

Although belonging to different theoretical frameworks, the results from the IMCS and the CCRT were highly convergent. In fact, both systems managed to distinguish a case (Claudia) that, despite achieving an adequate level of symptom functioning, most likely did not reach a stable and deeper change from a case (Barbara) that seems to have reached it, showing more elements of a narrative transformation. These transformations involved new forms of interpreting events and interacting with self and others. We can speculate as to whether these narrative changes are a mechanism of change or a consequence of the recovery of this client. In a recent study, the IMs predicted symptom improvement in the following session (Gonçalves et al., 2015) in a sample of narrative therapy. These results are in accordance with the notion that narrative changes can be a mechanism of therapeutic change (Angus \& Kagan, 2013).

The absence of significant narrative transformation in Claudia, at the level of both the micro(IMCS) and the macro-narrative (CCRT), probably had an impact at the follow-ups. We speculate that it is the absence of deeper narrative transformation during treatment that led to a relapse in Claudia, as assessed by the BDI-II. On the contrary, Barbara, who had a significant transformation 
in her self-narratives (at the level of IMs and the CCRT), maintained her gains. Despite the fact that Claudia's relapse could be due to external, unknown factors, we speculate that without significant changes at the self-narrative level, the risk of relapse is significantly higher, as occurred in this case. Further research could assess whether self-narrative changes, in fact, predict relapse at follow-up, as we are suggesting, which would be of great importance both from a theoretical as well a clinical perspective.

An alternative explanation for the difference of CCRT changes in both cases could be that whereas Barbara's problems were mainly interpersonal, Claudia's had to deal more with her own ability to cope with responsibilities and the fulfillment of her obligations. Therefore, whereas Barbara's therapeutic gains would reflect more plainly in her interpersonal patterns, Claudia's would not. This alternative explanation would also be congruent with the lack of changes reflected in the IMCS. However, and following Luborsky's (1998) claim that therapeutic progress will always be reflected in clients' interpersonal patterns to some extent, even if Claudia's problems had a less interpersonal nature, she would have achieved more mastery of her difficulties that would be more evident in her interactions with others, which should be reflected in the CCRT (and in the IMCS).

Another alternative interpretation is to claim that CBT therapeutic work was not expected to produce a change in the interpersonal problems, as identified by the CCRT. However, at least one previous study does not support this idea: Crits-Christoph (1998) reported, in a comparison of cognitive therapy and interpersonal therapy, that in the former the therapist would adjust therapeutic work to the client's needs, which is reflected in the interpersonal patterns. Our own results are congruent with this interpretation from Crits-Christoph, as Barbara, following the same therapeutic manual as Claudia, presented changes in the CCRT that are in line with previous literature.

Finally, another factor to be considered is the difference in the personality disorder traits. Recent studies (Dimaggio et al., 2013; Verheul, Bartak, \& Widiger, 2007; Wilberg, Hummelen, Pedersen, \& Karterud, 2008) have shown some evidence that the amount of personality disorder traits is a better predictor of outcome than the criteria of presence or absence of a personality disorder. Dimaggio and colleagues (2013) showed a significant association between increase in personality disorder traits and interpersonal problems as well as symptom severity. However, and in line with Verheul et al. (2007), the authors consider a cutoff of five personality disorders traits. This means that the associations found are only significant above that cutoff. So, although Claudia presented more traits than Barbara, they are both below the referred threshold, and can be considered pure Axis I clients (Dimaggio et al., 2013).

\section{Limitations and Implications}

Due to its exploratory nature, this study has several limitations that need to be addressed in forthcoming research. Despite being just a comparison between two cases, which limits the possibility of generalization, this study examines what seems to be a finding that contradicts the theory. This, ultimately, may help refine the theory, as suggested by Stiles $(2005,2009)$ in his proposal for theory-building case studies. Finally, the narrative analyses used only sessions transcripts, which means the results are dependent on the content of those sessions. An interesting alternative could be using narratives collected at both pre- and posttherapy, which could allow a more rigorous assessment of change in self-narratives. 
Having these limitations in mind, the findings in these cases need to be replicated in other cases and samples, as this study also addresses an important question that has been challenging researchers in psychotherapy for at least 50 years (see Strupp, 1963/2013): What do therapists and researchers mean when they refer to recovery or improvement? The field of psychotherapy outcome research has generally accepted the idea that outcomes should be measured at the symptom level (often with self-report measures). However, as Hill, Chui, and Baumann (2013) recently emphasized, measuring outcomes solely at this elementary level may overlook the complexities of psychotherapeutic change. The present study contributes to this discussion by emphasizing the importance of measuring self-narrative change in psychotherapy. Thus, two interesting questions for the future are whether measuring self-narrative change could be a more robust predictor of reliable change than the amelioration of symptoms, and whether this narrative change could also be an important factor in preventing relapse.

\section{FUNDING}

This article was supported by the Portuguese Foundation for Science and Technology (FCT), by the Grant PTDC/PSI-PCL/121525/2010 (Ambivalence and unsuccessful psychotherapy, 20122015) and by the PhD Grant SFRH/BD/77324/2011.

This study was conducted at Psychology Research Centre, University of Minho, and supported by the Portuguese Foundation for Science and Technology and the Portuguese Minister of Education and Science through national funds and when applicable co-financed by FEDER under the PT2020 Partnership Agreement (UID/PSI/01662/2013).

\section{REFERENCES}

Adler, J. M. (2012). Living into the story: Agency and coherence in a longitudinal study of narrative identity development and mental health over the course of psychotherapy. Journal of Personality and Social Psychology, 102(2), 367-389. doi: $10.1037 / \mathrm{a} 0025289$

Alves, D., Mendes, I., Gonçalves, M., \& Neimeyer, R. A. (2012). Innovative moments in grief therapy: Reconstructing meaning following perinatal death. Death Studies, 36, 795-818. doi:10.1080/07481187.2011.608291

American Psychiatric Association. (2002). DSM-IV-TR: Manual de diagnóstico e estatística das perturbações mentais [DSM-IV-TR: Diagnostic and statistical manual of mental disorders] (4th ed.). Lisboa, Portugal: Climepsi Editores.

Angus, L. E., \& Greenberg, L. S. (2011). Working with narrative in emotion-focused therapy: Changing stories, healing lives. Washington DC: American Psychological Association.

Angus, L. E., \& Kagan, F. (2013). Assessing client self-narrative change in emotion-focused therapy of depression: An intensive single case analysis. Psychotherapy, 50(4), 525-534. doi:http://dx.doi.org/10.1037/a0033358

Angus, L., Levitt, H., \& Hardtke, K. (1999). The narrative processes coding system: Research applications and implications for psychotherapy practice. Journal of Clinical Psychology, 55(10), 1255-1270.

Angus, L. E., \& Mcleod, J. (Eds.). (2004). The handbook of narrative psychotherapy: Practice, theory, and research. London, UK: Sage.

Baerger, D. R., \& McAdams, D. P. (1999). Life story coherence and its relation to psychological well-being. Narrative Inquiry, 9(1), pp. 69-96. doi:10.1075/ni.9.1.05bae

Barber, J., Crits-Christoph, P., \& Luborsky, L. (1998). A guide to CCRT standard categories and their classification. In L. Luborsky \& P. Crits-Christoph (Eds.), Understanding transference: The core conflictual relationship theme method (2nd ed., pp. 43-54). New York, NY: Basic Books.

Batista, J., Alves, D., Freitas, S. \& Machado, A. (2012). Manual of utilization of core conflictual relationship theme. Unpublished manuscript, University of Minho, Braga, Portugal. 
Beck, A. T., Rush, A. J., Shaw, B. F., \& Emery, G. (1979). Cognitive therapy of depression. New York, NY: Guilford.

Beck, A. T., Steer, R. A., \& Brown, G. K. (1996). Manual for Beck Depression Inventory II. San Antonio, TX: Psychological Corporation.

Bressi, C., Amadei, G., Caparrelli, S., Cattaneo, C., Cova, F., Crespi, S., ... Invernizzi, G. (2000). A clinical and psychodynamic follow-up study of crisis intervention and brief psychotherapy in psychiatric emergency. New Trends in Experimental and Clinical Psychiatry, 16(1/4), 31-37.

Ciaglia, D. (2010). The psychotherapy of drug dependence: Changes in core conflictual relationship themes. Unpublished doctoral dissertion, University of Wollongong, NSW, Australia. http://ro.uow.edu.ay/theses/ 3206

Cierpka, M., Strack, M., Benninghoven, D., Staats, H., Dahlbender, R., Pokorny, D., ... Albani, C. (1998). Stereotypical relationship patterns and psychopathology. Psychotherapy and Psychosomatics, 67(4/5), 241-248. doi: $10.1159 / 000012286$

Coelho, R., Martins, A. \& Barros, H. (2002). Clinical profiles relating gender and depressive symptoms among adolescents ascertained by the Beck Depression Inventory II. European Psychiatry, 17(4), 222-226. doi:10.1016/S09249338(02)00663-6

Crits-Christoph, P. (1998). The interpersonal interior of psychotherapy. Psychotherapy Research, 8(1), 1-16. doi:10.1080/10503309812331332157

Crits-Christoph, P., Connolly, M., Shappell, S., Elkin, I., Krupnick, J., \& Sotsky, S. (1999). Interpersonal narratives in cognitive and interpersonal psychotherapies. Psychotherapy Research, 9(1), 22-35. doi: 10.1080/10503309912331332571

Crits-Christoph, P., Demorest, A., Muenz, L. R., \& Baranackie, K. (1994). Consistency of interpersonal themes for patients in psychotherapy. Journal of Personality, 62(4), 499-526. doi:10.1111/j.1467-6494.1994.tb00307. $\mathrm{X}$

Crits-Christoph, P., \& Luborsky, L. (1998). Changes in CCRT pervasiveness during psychotherapy. In L. Luborsky \& P. Crits-Christoph (Eds.), Understanding transference: The core conflictual relationship theme method (2nd ed., pp. 151-163). Washington, DC: American Psychological Association.

Demorest, A., Crits-Christoph, P., Hatch, M., \& Luborsky, L. (1999). A comparison of interpersonal scripts in clinically depressed versus nondepressed individuals. Journal of Research in Personality, 33(3), 265-280. doi:10.1006/jrpe.1999.2246

Dimaggio, G. (2006). Disorganized narratives in clinical practice. Journal of Constructivist Psychology, 19(2), $103-108$. doi:10.1080/10720530500508696

Dimaggio, G., Carcione, A., Nicolò, G., Lysaker, P. H., d'Angerio, S., Conti, M. L., .. \& \& Semerari, A. (2013). Differences between axes depend on where you set the bar: Associations among symptoms, interpersonal relationship, and alexithymia with number of personality disorder criteria. Journal of Personality Disorders, 27(3), 371-382. doi:10.1521/pedi_2012_26_043

Dimaggio, G., Montano, A., Popolo, R., \& Salvatore, G. (2015). Metacognitive interpersonal therapy for personality disorders: A treatment manual. New York, NY: Routledge.

Dimaggio, G., Salvatore, G., Azzara, C., \& Catania, D. (2003). Rewriting self-narratives: The therapeutic process. Journal of Constructivist Psychology, 16(2), 155-181. doi:10.1080/10720530390117920

First, M. B., Gibbon, M., Spitzer, R. L., Williams, J., \& Benjamin, L. (1997). Structured clinical interview for DSM-IV Axis II personality disorders: SCID-II. Washington, DC: American Psychiatric Press.

First, M. B., Spitzer, R. L., Gibbon, M., \& Williams, J. B. W. (2002). Structured clinical interview for DSM-IV-TR Axis I disorders, research version, non-patient edition (SCID-I/NP). New York, NY: New York State Psychiatric Institute, Biometrics Research.

Gergen, K. J., \& Gergen, M. M. (1997). Narratives of the self. In L. Hinchman \& S. Hinchman (Eds.), Memory, identity, community: The idea of narrative in the human sciences (pp. 161-184). New York, NY: State University of New York.

Gonçalves, M. M., Matos, M., \& Santos, A. (2009). Narrative therapy and the nature of "innovative moments" in the construction of change. Journal of Constructivist Psychology, 22(1), 1-23. doi:10.1080/10720530802500748

Gonçalves, M. M., Mendes, I., Ribeiro, A., Angus, L., \& Greenberg, L. (2010). Innovative moments and change in emotional focused therapy: The case of Lisa. Journal of Constructivist Psychology, 23(4), $267-294$. doi:10.1080/10720537.2010.489758

Gonçalves, M. M., Mendes, I., Cruz, G., Ribeiro, A., Angus, L., \& Greenberg, L. (2012). Innovative moments and change in client-centered therapy. Psychotherapy Research, 22(4), 389-401. doi:10.1080/10503307.2012.662605 
Gonçalves, M. M., Ribeiro, A. P., Mendes, I., Matos, M., \& Santos, A. (2011). Tracking novelties in psychotherapy process research: The innovative moments coding system. Psychotherapy Research, 21(5), 497-509. doi:10.1080/10503307.2011.560207

Gonçalves, M. M., Ribeiro, A. P., Silva, J. R., Mendes, I., \& Sousa, I. (2015). Narrative innovations predict symptom improvement: Studying innovative moments in narrative therapy of depression. Psychotherapy Research (ahead-ofprint), 1-11. doi:10.1080/10503307.2015.1035355

Grenyer, B. F., \& Luborsky, L. (1996). Dynamic change in psychotherapy: Mastery of interpersonal conflicts. Journal of Consulting and Clinical Psychology, 64(2), 411-416. doi:http://dx.doi.org/10.1037/0022-006X.64.2.411

Hill, C. E., Chui, H., \& Bauman, E. (2013). Revisiting and reenvisioning the outcome problem in psychotherapy: An argument to include individualized and qualitative measurement. Psychotherapy, 50(1), 68-76. doi:10.1037/a0030571

Jacobson, N. S., \& Truax, P. (1991). Clinical significance: A statistical approach to defining meaningful change in psychotherapy research. Journal of Consulting and Clinical Psychology, 59(1), 12-19. doi:10.1037/0022-006X.59.1.12

Lambert, M. J., Burlingame, G. M., Umphress, V., Hansen, N. B., Vermeersch, D. A., Clouse, G. C., \& Yanchar, S. C. (1996). The reliability and validity of the outcome questionnaire. Clinical Psychology \& Psychotherapy, 3(4), 249-258. doi:10.1002/(SICI)1099-0879(199612)3:4<249::AID-CPP106>3.0.CO;2-S

Lopes, R. T., Gonçalves, M. M., Machado, P. P., Sinai, D., Bento, T., \& Salgado, J. (2014). Narrative therapy vs. cognitivebehavioral therapy for moderate depression: Empirical evidence from a controlled clinical trial. Psychotherapy Research, 24(6), 662-674. doi:10.1080/10503307.2013.874052

Luborsky, L. (1998). The early life of the idea for the core conflictual relationship theme method. In L. Luborsky \& P. Crits-Christoph (Eds.), Understanding transference: The core conflictual relationship theme method (2nd ed., pp. 151-163). Washington, DC: American Psychological Association.

Luborsky, L., Barber, J. P., \& Diguer, L. (1992). The meanings of narratives told during psychotherapy: The fruits of a new observational unit. Psychotherapy Research, 2(4), 277-290. doi:10.1080/10503309212331333034

Lysaker, P. H., Lancaster, R. S., \& Lysaker, J. T. (2003). Narrative transformation as an outcome in the psychotherapy of schizophrenia. Psychology and Psychotherapy: Theory, Research, and Practice, 76(3), 285-299. doi:10.1348/147608303322362505

Lysaker, P. H., Ringer, J., Maxwell, C., McGuire, A., \& Lecomte, T. (2010). Personal narratives and recovery from schizophrenia. Schizophrenia Research, 121(1), 271-276. doi:http://dx.doi.org/10.1016/j.schres.2010.03.003

Machado, P. P., \& Fassnacht, D. (2015). The Portuguese version of the Outcome Questionnaire (OQ-45): Normative data, reliability, and clinical significance cut-offs scores. Psychology and Psychotherapy: Theory, Research and Practice, 88(4), 427-437. doi: 10.1111/papt.1204

Machado, P. P. P., \& Klein, J. (2006). Outcome questionnaire-45: Portuguese psychometric data with a non-clinical sample. Paper presented at the 37th Annual Meeting of the Society for Psychotherapy Research, Edinburgh, Scotland.

Matos, M., Santos, A., Gonçalves, M. M., \& Martins, C. (2009). Innovative moments and change in narrative therapy. Psychotherapy Research, 19(1), 68-80. doi:10.1080/10503300802430657

McMullen, L., \& Conway, J. (1997). Dominance and nurturance in the narratives told by clients in psychotherapy. Psychotherapy Research, 7(1), 83-99. doi:10.1080/10503309712331331893

Mendes, I., Ribeiro, A. P., Angus, L. E., Greenberg, L. S., Sousa, I., \& Gonçalves, M. M. (2010). Narrative change in emotion-focused therapy: How is change constructed through the lens of the innovative moments coding system? Psychotherapy Research, 20(6), 692-701. doi:10.1080/10503307.2010.514960

Neimeyer, R. A. (2000). Narrative disruptions in the construction of self. In R. A. Neimeyer \& J. Raskin (Eds.), Constructions of disorder (pp. 207-242). Washington, DC: American Psychological Association.

Neimeyer, R. A., Herrero, O., \& Botella, L. (2006). Chaos to coherence: Psychotherapeutic integration of traumatic loss. Journal of Constructivist Psychology, 19(2), 127-145. doi:10.1080/10720530500508738

Pennebaker, J. (1993). Putting stress into words: Health, linguistic, and therapeutic implication. Behaviour Research \& Therapy, 31(6), 539-548. doi:10.1016/0005-7967(93)90105-4

Polkinghorne, D. E. (2004). Narrative therapy and postmodernism. In L. E. Angus \& J. McLeod (Eds.), The handbook of narrative and psychotherapy: Practice, theory, and research (pp. 53-68). Thousand Oaks, CA: Sage.

Ribeiro, A., Gonçalves, M. M., \& Ribeiro, E., (2009). Processos narrativos de mudança em psicoterapia: Estudo de um caso de sucesso de terapia construtivista [Narrative change in psychotherapy: A good-outcome case of constructivist therapy]. Psychologica, 50, 181-203.

Santos, A., Gonçalves, M. M., \& Matos, M. (2010). Innovative moments and poor outcome in narrative therapy. Counselling and Psychotherapy Research, 11(2), 129-139. doi:10.1080/14733140903398153 
Santos, A., Gonçalves, M. M., Matos, M., \& Salvatore, S. (2009). Innovative moments and change pathways: A good outcome case of narrative therapy. Psychology and Psychotherapy: Theory, Research, and Practice, 82(4), 449-466. doi: $10.1348 / 147608309 X 462442$

Sarbin, T. R. (1986). The narrative and the root metaphor for psychology. In T. R. Sarbin (Ed.), Narrative psychology: The storied nature of human conduct (pp. 3-21). New York, NY: Praeger.

Seggar, L. B., Lambert, M. J., \& Hansen, N. B. (2002). Assessing clinical significance: Application to the Beck Depression Inventory. Behavior Therapy, 33(2), 253-269. doi:10.1016/S0005-7894(02)80028-4

Singer, J. A. (2005). Personality and psychotherapy: Treating the whole person. New York, NY: Guilford.

Steer, R. A., Brown, G. K., Beck, A. T., \& Sanderson, W. C. (2001). Mean Beck Depression Inventory-II scores by severity of major depressive episode. Psychological Reports, 88(3c), 1075-1076. doi:10.2466/pr0.2001.88.3c.1075

Stiles, W. B. (2005). Case studies. In J. C. Norcross, L. E. Beutler, \& R. F. Levant (Eds.), Evidence-based practices in mental health: Debate and dialogue on the fundamental questions (pp. 57-64). Washington, DC: American Psychological Association.

Stiles, W. B. (2009). Logical operations in theory-building case studies. Pragmatic Case Studies in Psychotherapy, 5(3), 9-22. doi:10.14713/pcsp.v5i3.973.

Strupp, H. H. (2013). The outcome problem in psychotherapy revisited. Psychotherapy, 50(1), 3-11. (Originally published in 1963.) doi:10.1037/h0094491

Verheul, R., Bartak, A., \& Widiger, T. (2007). Prevalence and construct validity of personality disorder not otherwise specified (PDNOS). Journal of Personality Disorders, 21(4), 359-370. doi:10.1521/pedi.2007.21.4.359

White, M. \& Epston, D. (1990). Narrative means to therapeutic ends. New York, NY: Norton.

Wilberg, T., Hummelen, B., Pedersen, G., \& Karterud, S. (2008). A study of patients with personality disorder not otherwise specified. Comprehensive Psychiatry, 49(5), 460-468. doi:10.1016/j.comppsych.2007.12.008

Wilczek, A., Weinryb, R. M., Barber, J. P., Gustavsson, J. P., \& Åsberg, M. (2004). Change in the core conflictual relationship theme after long-term dynamic psychotherapy. Psychotherapy Research, 14(1), 107-125. doi:10.1093/ptr/kph007

Young, J. E. (1999). Cognitive therapy for personality disorders: A schema-focused approach. Sarasota, FL: Professional Resources Press. 